39 (2) | 2010

Varia

Lima, 30 de agosto-2 de septiembre de 2010

Simposio Internacional: «Cultura visual y revolución: Hispanoamérica, 1808-1830»

Lima, 30 de agosto-2 de septiembre de 2010

Georges Lomné

\title{
OpenEdition
}

Journals

Edición electrónica

URL: http://journals.openedition.org/bifea/2055

DOI: 10.4000/bifea.2055

ISSN: 2076-5827

Editor

Institut Français d'Études Andines

Edición impresa

Fecha de publicación: 1 agosto 2010

Paginación: 467-474

ISSN: 0303-7495

Referencia electrónica

Georges Lomné, « Simposio Internacional: «Cultura visual y revolución: Hispanoamérica,

1808-1830» », Bulletin de l'Institut français d'études andines [En línea], 39 (2) | 2010, Publicado el 01 febrero 2011, consultado el 07 noviembre 2020. URL : http://journals.openedition.org/bifea/2055 : DOI : https://doi.org/10.4000/bifea.2055

Les contenus du Bulletin de l'Institut français d'études andines sont mis à disposition selon les termes de la licence Creative Commons Attribution - Pas d'Utilisation Commerciale - Pas de Modification 4.0 International. 


\section{SIMPOSIO INTERNACIONAL: «CULTURA VISUAL Y REVOLUCIÓN: HISPANOAMÉRICA, 1808-1830»}

Lima, 30 de agosto-2 de septiembre de 2010

Este simposio internacional fue convocado por la directora del Museo de Arte de Lima (MALI), Natalia Majluf, y co-organizado por Jean-Joinville Vacher - responsable de la Cooperación regional para los países andinos en la Embajada de Francia-, la Embajada de Chile en el Perú y la Fundación Getty. También recibió el apoyo de la Agencia Española de Cooperación Internacional para el Desarrollo (AECID), del Programa de Maestría en Historia del Arte de la Pontificia Universidad Católica del Perú (PUCP) y del Instituto Francés de Estudios Andinos (IFEA, UMIFRE 17, CNRS-MAEE). Después de una sesión inaugural en el MALI, el lunes 30 de agosto en la noche, el simposio se desarrolló durante los dos días siguientes en el auditorio de Ciencias Sociales de la PUCP. La sesión de «Relatoría y balance» tuvo lugar el 2 de septiembre en el auditorio de Humanidades de esta misma universidad. En suma este evento permitió reunir a 17 conferencistas y 8 comentaristas de diversos países hispanoamericanos, de España y Francia. Los

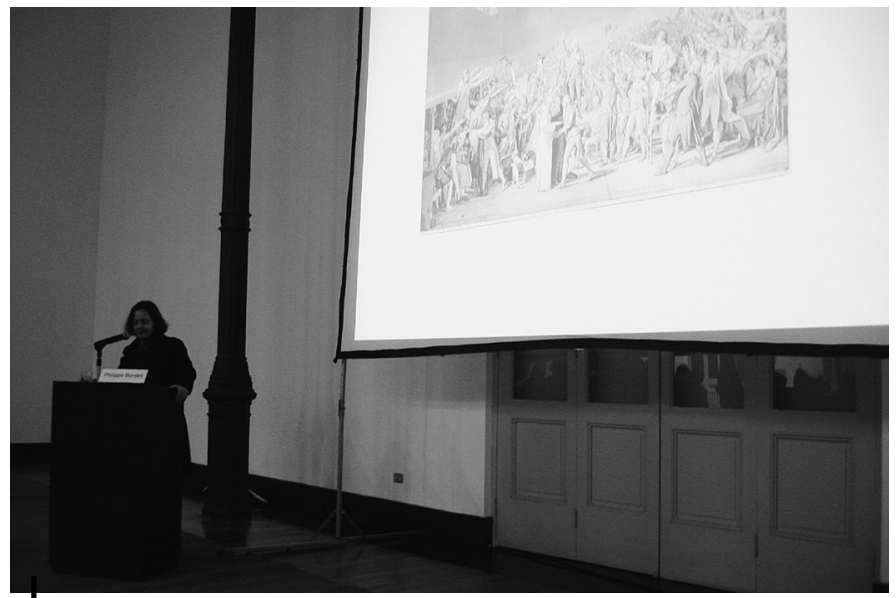

Apertura del Simposio por Natalia Majluf

MALI, Lima, 31 de agosto de 2010.

Foto del autor. oyentes eran, en su mayor parte, integrantes de la Maestría en Historia del Arte de la PUCP. Conviene recalcar que, por la calidad y originalidad de sus aportes científicos, este simposio descolló entre los muchos encuentros académicos que ya tuvieron lugar en los países andinos con ocasión del Bicentenario de las Independencias. Quizás por la verdadera «revolución historiográfica» a la cual apeló Natalia Majluf durante la sesión inaugural y que podría resumirse en este interrogante: ¿cómo pensar de otra manera el vínculo entre imagen e independencia? 
En el simposio se presentaron dos perspectivas distintas. Una esbozó los resultados del proyecto colectivo de investigación llevado a cabo con el apoyo de la Fundación Getty: "José Gil de Castro [1785-1841 n.d.a.]. Cultura visual y representación, del antiguo régimen a las repúblicas sudamericanas». La otra brindó elementos que permitieran escribir una historia comparativa de la cultura visual durante la época de transición, dentro y fuera del orbe hispano. Obviamente, no podemos transcribir aquí la riqueza de cuatro días de debate. Solo destacaremos tres enseñanzas científicas muy significativas, entre otras.

La primera versa sobre la metamorfosis de los códigos de la representación heroica. Se estableció que en pocos años, los retratos alegóricos y estáticos del periodo colonial dieron paso a retratos de gran sobriedad, que enfatizaban la energía de los tiempos nuevos. En otras palabras, el lenguaje cifrado del antiguo régimen fue sustituido por símbolos de fácil alcance para el común: escarapelas o cintas patrióticas, miradas inquietas y gestos apasionados. En suma, en pos del modelo francés del retrato republicano, que presentó Philippe Bordes1 durante la conferencia inaugural del simposio, amaneció una dignidad nueva, hecha toda de responsabilidad ciudadana.

Con el afán de contextualizar la dinámica de esta mutación en el tiempo largo, Luis Eduardo Wuffarden se consagró a recalcar la importancia de los códigos pictóricos introducidos en Lima por Cristóbal Lozano (inicios del XVIII-1776), y sus seguidores Cristóbal de Aguilar y Pedro Díaz, pintores todos de la Corte virreinal en la segunda mitad del siglo XVIII. Esta filiación sería esencial para entender el arte de José Gil de Castro pero haría caso omiso, según Natalia Majluf, de la tradición cuzqueña y de nuevos códigos pictóricos europeos que pudieron ejercer cierta seducción. El acercamiento de Wuffarden fue completado por Ricardo Kusunoki. Este investigador del MALI, vinculado al proyecto Gil de Castro, presentó el proyecto neoclásico de Matías Mateo en Lima como una respuesta estética, de 1794 a 1808, a la crisis del antiguo régimen y del catolicismo. Algo que recalcó luego Ramón Mújica Pinilla, miembro de la Academia Nacional de Historia (Perú), subrayando el matiz local del Buen Gusto y su importancia como eslabón entre el registro de la Roma clásica y el de la Jerusalén santa. Promovido por el virrey Abascal, este último registro sería posteriormente asociado a los libertadores San Martín y Bolívar, como Mesías de la libertad. Por lo tanto, en vísperas de la independencia, los retratos fueron mayormente dedicados a representar la santidad y, muy en particular, la de Santa Rosa de Lima.

Después de la tormenta revolucionaria se impuso otro tipo de representación, de corte secular y burgués. Luis Eduardo Wuffarden recalcó por una parte que la novedad del «medio busto» triunfó definitivamente. Por otra parte, hizo notar

1 Director científico del INHA (Institut National de I'Histoire de l'Art, París). Autor de Le Serment Du Jeu De Paume de Jacques-Louis David: Le peintre, son milieu et son temps, de 1789 a 1792, 1983; La Révolution par la gravure : Les tableaux historiques de la Révolution française, une entreprise éditoriale d'information et sa diffusion en Europe (1791-1817), 2002; Portraiture in Paris Around 1800: Cooper Penrose by Jacques-Louis David, 2004; Jacques-Louis David: Empire to exile, 1995; Catálogo de la muestra del J. P. Getty Museum y del Sterling y Francine Clark Institute, 2007. 
que varios héroes chilenos y argentinos fueron pintados por Gil de Castro según un gusto chileno distinto, por su libertad de expresión, del gusto imperante en Lima. En este mismo registro, Víctor Mínguez Cornelles, de la Universidad Jaume I de Castellón, España, recalcó cómo José Bonaparte se hizo retratar como un tranquilo hacendado durante su estadía final en Filadelfia. Beatriz González Aranda, pintora y asesora del Banco de la República de Colombia, mostró cómo el abanderado Espinosa retrató a Bolívar, en sus últimos cuadros, como un héroe devuelto a su condición civil enfatizando, incluso, el pesar de sus enfermedades. Para cerrar este primer rubro, es interesante destacar la demostración de Laura Malosetti Costa, investigadora uruguaya del Conicet y profesora en el Universidad de Buenos Aires (UBA), con respecto a la posteridad de Gil de Castro. A finales del siglo XIX, se llegó a considerarle como «un inculto pintor atrasado». Los argentinos lo repudiaron arguyendo el carácter estereotipado de sus cuadros y los chilenos por ser mal pintor. El criterio actual de su rescate se atiene precisamente a valorar la autenticidad de sus cuadros, ajena a los padrones heroicos del siglo XIX. Luis Eduardo Wuffarden hizo notar al respecto que la fama de Gil de Castro en el Perú evolucionó en función de los usos del pasado. Por ende, se le valoró en 1892, en 1921 y después de 1944.

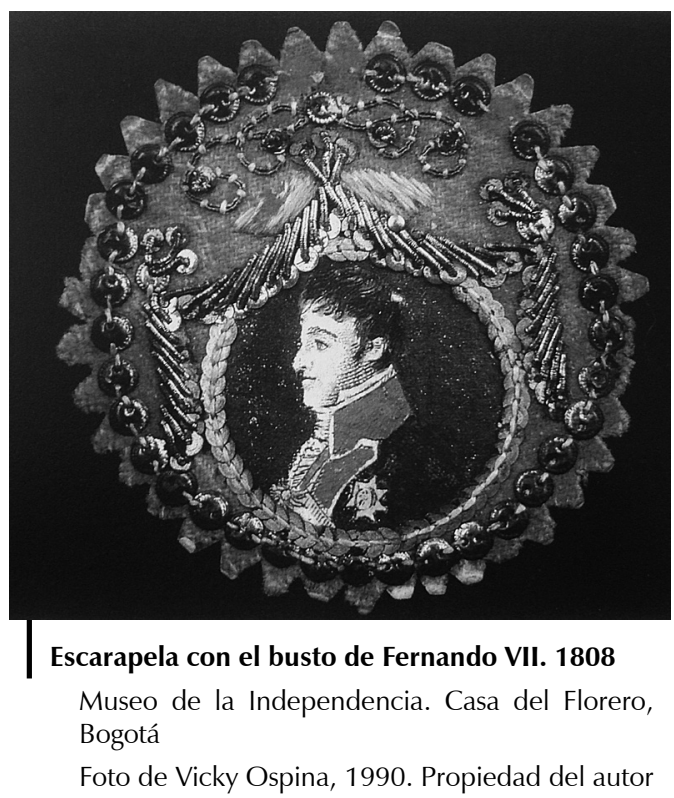

La segunda enseñanza del simposio versa sobre el proceso de elaboración del retrato heroico. Varios ponentes y comentaristas pusieron de relieve el afán propagandístico de las representaciones. Beatriz González abrió el fuego reflexionando sobre el proceso de invención icónica de la figura de Bolívar en Bogotá, a partir de 1819. Pedro José Figueroa y José María Espinosa dieron luz a dos tradiciones icónicas divergentes: una, de corte más clásico, otra más romántica. Al enfatizar la preponderancia, en el Perú mismo, de la imagen pintada de Bolívar sobre las de San Martín u O'Higgins, Scarlett O'Phelan, de la PUCP, subrayó casos 
anteriores de propaganda visual bien lograda. Recordó muy en particular cómo Túpac Amaru se hacía preceder por su propio retrato, adornado de insignias incaicas, antes de llegar en persona al Alto Perú. Víctor Mínguez se interrogó al contrario sobre la incapacidad de los retratos de José Bonaparte de convencer al pueblo español que él pudiera ser el agente de su regeneración. De igual manera, Jaime Genaro Cuadriello Aguilar, profesor del Instituto de Investigaciones Estéticas de la UNAM, se interrogó sobre la dudosa eficacia de los retratos de Iturbide y del «álbum de la Libertad», confeccionado e impreso en París con ocasión de su coronamiento en México, en 1822. Cosa singular: Iturbide, considerado como «genio tutelar» de su nación antes que Hidalgo ocupara este sitio, sufrió una rápida repudiación. Víctor Mínguez dijo su interés por la secuencia propagandística del coronamiento establecida ahora en su totalidad gracias a las acuarelas recién descubiertas en Suiza. El súbito desmoronamiento de la imagen de Iturbide en 1823 se habría de entender, quizás, por el poco heroísmo que la sustentaba, a diferencia de Napoleón su modelo explícito. En este sentido, Beatriz González y Georges Lomné destacaron la singularidad de la imagen de Bolívar por el carácter sagrado que le ha sido asociado de manera duradera.

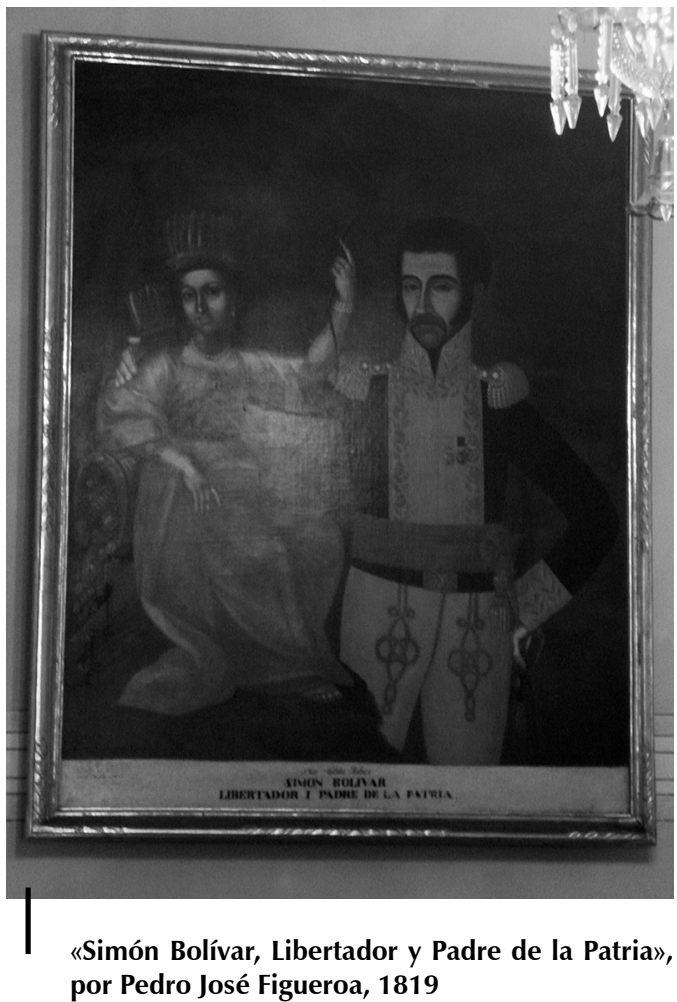

Casa Museo Quinta de Bolívar, Bogotá, octubre de 2010

Foto del autor
Todo esto no ocultó la existencia de prototipos en el proceso mismo de fabricación de las imágenes heroicas. Beatriz González enseñó cómo Figueroa utilizó un padrón monárquico para pintar a Bolívar y cómo, en el caso del famoso cuadro «Simón Bolívar, Libertador y Padre de la Patria» (1819) el héroe del siglo sustituyó a una figura de Fernando VII en función del revés de la batalla de Boyacá. Gil de Castro practicó lo mismo sustituyendo al virrey Abascal por San Martín en un cuadro conservado en Santiago de Chile. Néstor Barrio, de la Universidad Nacional de San Martín en Argentina, mostró cómo las técnicas actuales de análisis científico de los cuadros ponían en evidencia, en el caso de Gil de Castro, la fabricación en cadena de retratos sobre bustos de dimensiones estandarizadas. Sin embargo afirmó que existía un «sello» pictórico propio de este pintor.

Una tercera enseñanza abarca la dimensión patriótica de las representaciones. Los retratos de los virreyes enseñaban un ethos al servicio de Dios, del Rey y del bien común. En 
suma, lo que pronto se llamaría el «verdadero patriotismo» frente al patriotismo de corte republicano traído por los vientos de libertad atlánticos. Luis Eduardo Wuffarden nos enseñó cómo, en 1758, Lozano pintó a Manso de Velasco, Conde de Superunda, en el escenario de la Plaza Mayor de Lima, transformada esta en una ciudad civilizada, de aire cosmopolita. El gusto remitía obviamente a la «gran manera europea», pero de un academismo endógeno anterior a la fundación misma de la Academia de San Fernando en Madrid. Luego, entre 1780 y 1807, Pedro Díaz pintó a todos los virreyes. Su obra maestra, el retrato de Ambrosio O'Higgins en 1798, mostraba un arco triunfal de apariencia pétrea, que simbolizaba la renovación de la ciudad. En un espíritu similar, su retrato de Fernando de Abascal y Souza ostentaba en una mesa de trabajo los planos de las murallas y los del nuevo Cementerio General de Lima.

Por haberse sustituido la Nación al Rey, la semiótica del patriotismo sufrió una metamorfosis abriéndose al registro de los «emblemas de la razón» (Starobinski 1988) y a una obvia militarización. Acerca de esta, Roberto Amigo Cerisola, de la Facultad de Filosofía y Letras de la UBA, hizo notar el impacto de la reorganización de las milicias en las postrimerías del siglo XVIII. Por ende, habría que relativizar la influencia de un modelo francés en cuanto al brote de una iconografía militar. Adelantó entonces el ejemplo de los retratos de Puyredón, el reorganizador de las milicias en Buenos Aires, a partir de 1806. Conviene decir de paso que Scarlett O'Phelan hizo notar la sorpresa de Alejandro de Humboldt, en 1802, frente al uso del uniforme militar por parte de la «clase alta» limeña para marcar sus privilegios. También apuntó la historiadora peruana que el uniforme militar había reemplazado a los hábitos de San Francisco para vestir a los muertos, en las postrimerías del siglo XVIII. En pos de la ponencia de Roberto Amigo, Cecilia Méndez, de la Universidad de California, recalcó la importancia de las milicias como crisol de un ideario de valor que terminaría convirtiéndose en un patriotismo de corte republicano. En esta vena, Hugo Contreras Cruces, de la Universidad de Chile, describió el Batallón Infantes de la Patria, una milicia de pardos a la cual perteneció Gil de Castro como capitán de fusileros. Como lo recalcó Jesús Cosamalón Aguilar, de la PUCP, el ángulo muerto de la historiografía de los afrodescendientes en la Independencia del Perú contribuye a corroborar la opinión expresada por Luis Eduardo Wuffarden de que Gil de Castro no es todavía hoy sino un «retratista sin rostro». Luego, Juan Manuel Martínez, del Museo Histórico Nacional de Chile, recalcó la importancia de la parafernalia de las decoraciones militares en los cuadros de Gil de Castro. El pintor estaba en Santiago en 1815 cuando Don Manuel Osorio inundó la ciudad de emblemas monárquicos que cada quién podía coser en su sombrero o vestido. Presenciaría más tarde la manera con la cual el libertador O'Higgins borró de la ciudad los escudos nobiliarios. Fueran monárquicos o patriotas, Gil de Castro siempre colocó estos signos en sus cuadros con mucho esmero. De manera general, el trueque de la cinta de la orden de Carlos III por la de San Martín indicaba a ojos de los patriotas, según Roberto Amigo, el pase de la Hidalguía al Valor.

Sin embargo, un lugar retórico permaneció inmutable en el corazón mismo del dispositivo de la gloria: la figura del «padre de la patria». Georges Lomné, 
director del IFEA, disertó sobre la ambigüedad de esta supervivencia. La parafernalia simbólica y el relato propio de la «imagen del libertador» quisieron distanciarse de los del «retrato del Rey», en el sentido amplio que atribuía Louis Marin a esta expresión. Pero este esfuerzo hizo caso omiso de la supervivencia de «monumentos de la gloria» idénticos, que seguían bebiendo de las fuentes clásicas. Esto explica cómo la imagen del Libertador pudo sustituirse con eficacia a la imagen del Rey utilizando el mismo «lugar de memoria». Esta fácil permutación explicaría la violencia de la damnatio memoriae de la imagen del otro durante la guerra de Independencia, muy en particular en Colombia. Víctor Mínguez había disertado ya sobre la verdadera «guerra de imágenes» alrededor de la figura de José I. Las caricaturas inglesas hicieron que la perdiera y quedara asociado para siempre al «rey de copas» o a «Pepe Botellas» en vez de serlo al majestuoso cuadro pintado por François Gérard (Museo de Fontainebleau, 1810), a imitación del Retrato de Luis XIV de Hyacinthe Rigaud (Louvre, 1700), o al cuadro de JeanBaptiste Joseph Wicar donde aparecía, en uniforme de coronel de su propia guardia (Museo Nacional de Versalles, 1808), como regenerador de España, y su nuevo arquitecto. Al respecto, Cristóbal Aljovín de Losada enfatizó el efecto demoledor de la caricatura por dirigirse a un «público menor» cuando la imagen oficial se dirigía más a un «público mayor». La legitimidad política podía entonces ser arruinada por el solo registro de los vicios privados. Natalia Majluf colocó la reflexión en un nivel mayor de abstracción al plantear «De cómo reemplazar a un Rey. Retrato, visualidad y poder en la crisis de la independencia, 1808-1830». La directora del MALI evocó la furia iconoclasta, que nos priva hoy en día de muchos cuadros de Fernando VII, antes de interrogarse sobre la sustitución del retrato del Rey por el escudo nacional. El dibujo del escudo peruano por Gil de Castro en 1827, a pedido del Tribunal de Justicia de Lima, ¿no pondría así un punto final a la trayectoria del pintor y de una época?

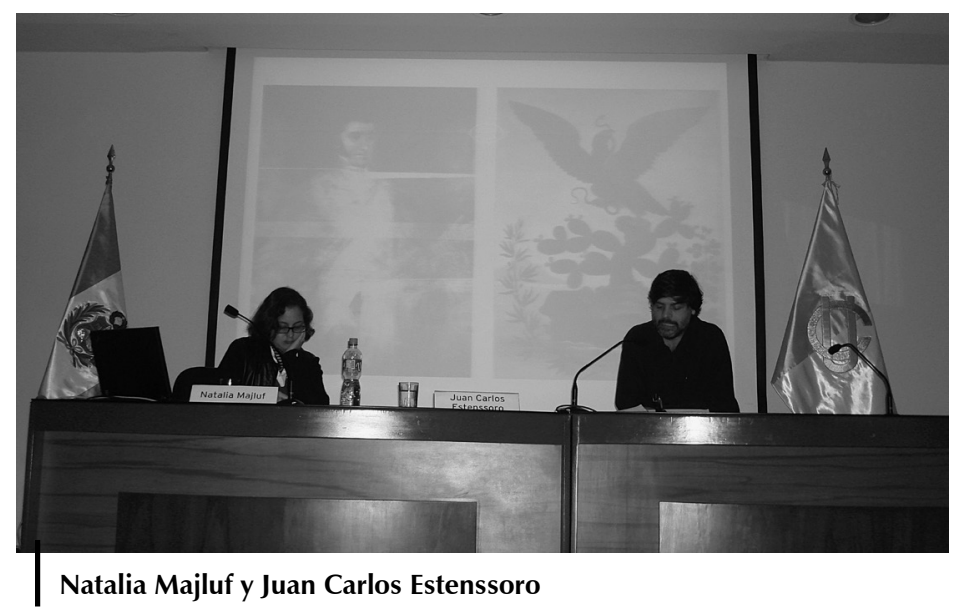

Sesión del 1ero de septiembre 2010

Foto del autor 
La relatoría general del simposio estuvo a cargo de Jaime Cuadriello, Juan Carlos Estenssoro, de la Universidad de Lille-III, y Georges Lomné. De entrada, Jaime Cuadriello destacó la virtud interdisciplinaria del proyecto Gil de Castro —un «nuevo paradigma del conocimiento en la América Latina»- y expresó su ansia hacia la futura exposición y su catálogo razonado. Disertó luego sobre la eficacia del modus operandi de Gil de Castro. Aquello que nos ofreció este pintor no sería sino una biografía colectiva que yace todavía en su galería de retratos. En fin, la guerra de las imágenes fue reemplazada por Gil de Castro por una perfecta «gestión de las imágenes». Juan Carlos Estenssoro destacó primero el peso de las mutaciones en la cultura visual. Recalcó que Santiago de Chile por no ser «ciudad de corte» pudo inventar una radicalidad nueva del retrato, nutrida de intimidad. Gil de Castro, al extraerse del academismo limeño, pudo beber de la fuente de esta revolución visual. Luego, planteó el problema del retrato del Rey y se interrogó sobre el matiz que existe entre borrar y sustituir la imagen del monarca por la de un héroe republicano. Terminó su relatoría pidiendo que se hiciera una antropología del retrato y destacó el innegable valor testimonial de la obra de Gil de Castro ya que a diferencia de muchos retratos del Antiguo Régimen, conocemos la identidad de quienes han sido pintados. Georges Lomné destacó luego el interés de conectar las reflexiones del simposio a la dinámica identificada hace años por Tzvetan Todorov del paso de la metáfora al símbolo (1993). El registro de las pasiones, encarecido por las revoluciones, se acomoda mejor del símbolo que de la alegoría. Por ende, el mundo cifrado se desvaneció a favor de otro, lleno de energía y habitado por la inquietud de corte lockeano que había destacado Jean Starobinski como crisol de la «invención de la libertad» (1964). El cuadro de David, Bonaparte cruzando los Alpes por el San Bernardo (Museo del Castillo de Versalles, 1800-1801), ¿no sirvió acaso de modelo a la representación

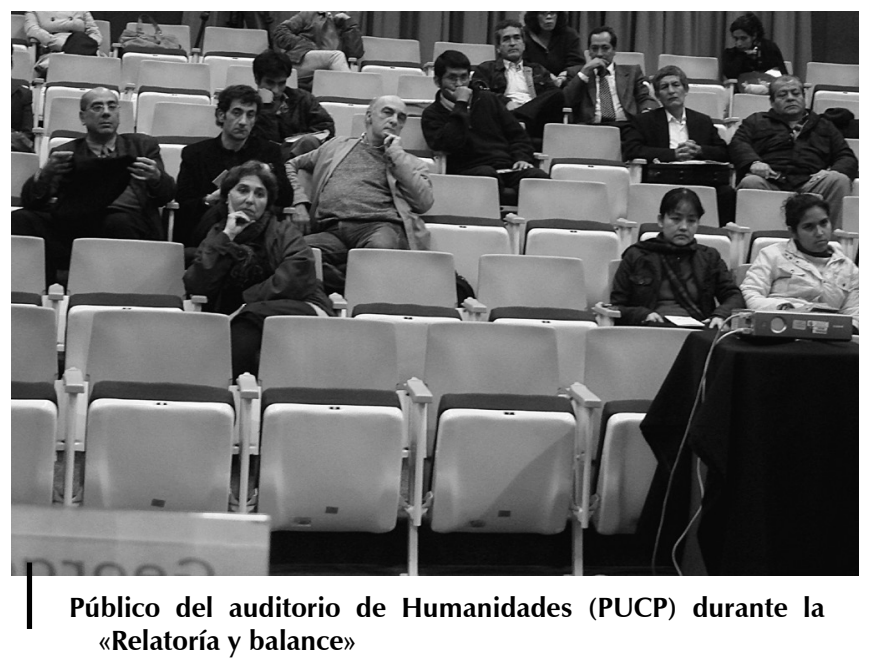

2 de septiembre de 2010

Foto del autor 
estereotipada de los Libertadores después de haberlo sido de algunas estatuas ecuestres de Carlos IV? Sin embargo, la eficiencia de la imagen del poder se sitúa más allá de meros códigos formales. De lo contrario, José I o Iturbide hubieran superado en gloria a cualquier otro. Al fin y al cabo, la política no es sino un asunto estético. El modelo limeño de Matías Mateo, al mezclar el Buen Gusto y el ideario agustino de la Jerusalén santa se conjugaba nítidamente con el proyecto de José de Ezpeleta y José Martínez Compañón en Santafé de Bogotá. Este crisol de patriotismo monárquico contribuiría luego a conformar otro patriotismo, de corte republicano. El éxito de la imagen de Bolívar, frente a otras, se debería quizás al hecho que encarnó mejor la nación - Colombia - que otros encarnaron la suya, y se hizo símbolo sin otro rodeo. Iturbide y José I quedarían para siempre vanas alegorías, frente a Hidalgo o Fernando VII, y San Martín sufriría de su palinodia monárquica y de la competencia de la nación abstracta que llegó a simbolizar el escudo del Perú.

\section{Referencias citadas}

BORDES, P., 1983 - Le Serment Du Jeu De Paume de Jacques-Louis David : Le peintre, son milieu et son temps, de 1789 a 1792, 265 pp.; París: Éditions de la Réunion des musées nationaux.

BORDES, P., 1995 - Jacques-Louis David: Empire to exile; New Haven, Londres et Williamstown.

BORDES, P., 2002 - La Révolution par la gravure : Les tableaux historiques de la Révolution française, une entreprise éditoriale d'information et sa diffusion en Europe (17911817), 318 pp.; parís: Musée de la Révolution française.

BORDES, P., 2004 - Portraiture in Paris Around 1800: Cooper Penrose by Jacques-Louis David, 80 pp.; San Diego: Putnam Foundation.

BORDES, P., 2007 - Catálogo de la muestra del J. P. Getty Museum y del Sterling y Francine Clark Institute, 379 pp.; Yale University Press.

STAROBINSKI, J., 1964 - La invención de la libertad, 222 pp.; Barcelona: Skira. Trad. de F. Olmos García Carroggio.

STAROBINSKI, J., 1988 - Los emblemas de la razón, 195 pp.; Madrid: Taurus. Trad. De José Luís Checa Cremades.

TODOROV, T., 1993 - Teorías del símbolo; Caracas: Monte Ávila.

Georges LOMNÉ 